\title{
Short Communication: A Potential Antiapoptotic Phenotype in Neutrophils of Cows Milked Once Daily in Early Lactation
}

\author{
C. J. Keane, ${ }^{\star} \|$ A. J. Hanlon, ${ }^{\star}$ J. F. Roche, ${ }^{\star} \|$ J. L. Burton,† J. F. Mee,‡ \\ J. V. O’Doherty, $\S$ and T. Sweeney* $\|^{1}$ \\ *Department of Animal Husbandry and Production, Faculty of Veterinary Medicine, University College Dublin, \\ Dublin 4, Ireland \\ †Immunogenetics Laboratory, Department of Animal Science, Michigan State University, East Lansing 48824 \\ $\ddagger$ Teagasc, Moorepark Research Centre, Fermoy, Co. Cork, Ireland; \\ $\S$ Department of Animal Science and Production, Faculty of Agriculture, Food and the Environment, \\ University College Dublin, Dublin 4, Ireland \\ ||The Conway Institute of Biomolecular and Biomedical Research, University College Dublin, Dublin 4, Ireland
}

\begin{abstract}
The objectives of this experiment were to compare the circulating concentrations of cortisol and determine whether these correlated with the expression profiles of a set of candidate apoptosis genes in neutrophils of Holstein-Friesian cows milked once vs. 3 times daily for $28 \mathrm{~d}$ postpartum. Cows on the once-daily milking regimen had significantly higher plasma cortisol concentrations on d 3,14 , and 28 postpartum than did those milked 3 times daily. On d 3 postpartum, when differences in cortisol and neutrophil counts were highest between the groups, mean mRNA abundance of nuclear factor $\kappa \mathrm{B}$ p65 subunit, $\mathrm{I} \kappa \mathrm{B} \alpha$, X-linked inhibitor of apoptosis; and heat shock protein 70 were higher in neutrophils of the cows milked once daily than in cows milked 3 times daily. However, no correlations were detected among plasma cortisol concentration, neutrophil count, or neutrophil gene expression in this study. Results suggest that the modest neutrophilia associated with once daily milking of cows immediately postpartum may be related to modifications in the cells' apoptotic program by factors other than cortisol.

Key words: neutrophil, apoptosis, bovine
\end{abstract}

Neutrophils are mature, terminally differentiated cells with a short circulatory half-life of 6 to $10 \mathrm{~h}$. This short half-life is explained by a constitutive program of spontaneous and death receptor-mediated apoptosis in these terminally differentiated leukocytes, although the life span of a neutrophil can be extended for 24 to $48 \mathrm{~h}$ by certain hormonal and proinflammatory factors present in blood (Chang et al., 2004; Madsen et al., 2004) and at sites of tissue infection (Lee et al., 1993). Glucocorticoid hormones, such as cortisol and dexa-

Received December 13, 2004.

Accepted September 26, 2005.

${ }^{1}$ Corresponding author: torres.sweeney@ucd.ie methasone, are known to alter neutrophil metabolism and gene expression during the stress of parturition and in response to steroid therapy (Chang et al., 2004; Weber et al., 2004). Glucocorticoids also prolong the survival of neutrophils in vivo and in vitro, via inhibition of normal programs of spontaneous and death receptor-induced apoptosis (Chang et al., 2004; Burton et al., 2005). Prolonged neutrophil survival is accompanied by increased blood neutrophil counts in vivo because circulating cells remain viable for longer than normal (Chang et al., 2004; Madsen et al., 2004).

Recently, we observed that neutrophil numbers were elevated in the blood of cows milked once daily in the postpartum period in comparison with cows milked 3 times daily (Keane et al., accepted). We characterized these neutrophils as predominantly segmented cells and, thus, mature (our unpublished data). We hypothesized that these cells might have been induced to express an anti-apoptotic genetic program, possibly under the influence of elevated blood cortisol that accompanied the neutrophilia in the once-daily milked cows. The main objective of this study was to elucidate possible relationships among blood cortisol concentrations, neutrophil counts, and neutrophil expression of several candidate apoptosis regulatory genes in cows milked once vs. 3 times daily in the early postpartum period.

Spring-calved Holstein-Friesian dairy cows from the herd at Teagasc, Moorepark Research Center (Fermoy, Co. Cork, Ireland) were blocked 2 wk prior to expected calving date according to parity (second lactation and greater than second lactation), previous milk yield, body condition score, and expected calving date and were then randomly assigned to 1 of 2 treatments: oncedaily milking $(\mathrm{n}=4)$ or 3 times daily milking $(\mathrm{n}=$ 4) for the first $28 \mathrm{~d}$ of lactation. This experiment was conducted under license according to the Cruelty to Animals Act (1876) in Ireland. Blood samples for plasma cortisol and neutrophil isolations were collected on d 3,14 , and 28 of lactation. Neutrophils were isolated 
Table 1. Gene targets and primer sequences

\begin{tabular}{|c|c|c|c|}
\hline Target $^{1}$ & Sequence & $\begin{array}{l}\text { Size of } \\
\text { amplicon } \\
\text { (bp) }\end{array}$ & $\begin{array}{l}\operatorname{Tm}^{2} \\
\left({ }^{\circ} \mathrm{C}\right)\end{array}$ \\
\hline $\mathrm{I} \kappa \mathrm{B} \alpha$ & for 5' GGCCAGCTGACACTAGAAAACCT 3' & 82 & 81 \\
\hline $\mathrm{I} \kappa \mathrm{B} \alpha$ & rev 5' CCGTGAACTCTGACTCTGTGTCAT3' & & \\
\hline $\mathrm{NF} \kappa \mathrm{B}$ p65 subunit & for 5' CTGTGCGTGTCTCCATGCA 3' & 81 & 85 \\
\hline $\mathrm{NF} \kappa \mathrm{B}$ p65 subunit & rev 5' TATCTGGCAGGTACTGGAATTCC 3' & & \\
\hline HSP70 & for 5' CGTGATGACCGCCCTGAT 3' & 89 & 85 \\
\hline HSP70 & rev 5' CGCCCGGCTGGTTGT 3' & & \\
\hline XIAP & for 5’ AGTGCTTTTGTTGTGGTGGAAA 3' & 78 & 78 \\
\hline XIAP & rev 5' GAAAGTGTCGCCTGTGTTCTGA 3' & & \\
\hline$\beta$-actin & for 5' CGCCATGGATGATGATATTGC 3' & 66 & 84 \\
\hline$\beta$-actin & rev 5' AAGCGGCCTTGCACAT 3' & & \\
\hline
\end{tabular}

${ }^{1} \mathrm{NF} \kappa \mathrm{B}=$ nuclear factor $\kappa \mathrm{B}$; HSP $=$ heat shock protein; XIAP $=\mathrm{X}$-linked inhibitor of apoptosis.

${ }^{2} \mathrm{Tm}=$ Melting temperature.

from whole blood by Percoll density gradient centrifugation, according to the protocol of Weber et al. (2004). Total RNA was extracted from the neutrophils using TRI Reagent (Sigma-Aldrich, Dublin, Ireland) according to the manufacturer's instructions. Synthesis for cDNA was performed using SuperScript First Strand Synthesis System for reverse transcription (RT)-PCR (Invitrogen Ltd., Paisley, UK). Quantitative RT-PCR analyses were then performed using an ABI PRISM 7900HT sequence detection system instrument and SDS 2.1 software (Applied Biosystems, Foster City, CA). The primer pairs for each candidate gene (Table 1) were designed from bovine sequences using Primer Express software (Applied Biosystems) and were commercially synthesized (Sigma Genosys, Cambridgeshire, UK). All samples were assayed in duplicate, and each amplification reaction was performed using 4ng of starting cDNA and SYBRGreen PCR core reagents for detection (Applied Biosystems). Plasma samples collected during the neutrophil isolation procedure were assayed for cortisol using the Corti-Cote cortisol antibody coated tube $\mathrm{I}^{125}$ radioimmunoassay kit (ICN Biomedicals, Inc., Hampshire, UK).

Cortisol concentration data were statistically analyzed using GLM repeated measures ANOVA (SAS Institute, 1989); treatment was the between-subject factor, and time was the within-subject factor. The RTPCR analysis was performed using the $2^{-\Delta \delta \mathrm{Ct}}$ method (Livak and Schmittgen, 2001); $\beta$-actin served as the control gene, and gene expression on $\mathrm{d} 3$ of lactation was the calibrator against which expression on $\mathrm{d} 14$ and 28 were compared. Differences in relative mRNA abundance were analyzed by repeated measures analysis using the PROC MIXED of SAS. Cow and error were random effects, and treatment, time, and treatment $\times$ time were fixed effects. Correlations between plasma cortisol, neutrophil count, and neutrophil gene expression were analyzed using PROC CORR of SAS to deter- mine Pearson product moment correlations across the whole data set.

As expected, cows in the once-daily milking group had significantly higher plasma cortisol concentrations $(P<0.05)$ on $\mathrm{d} 3,14$, and 28 postpartum than cows milked 3 times daily (Figure 1). Cortisol is considered to be the classical endocrine marker of stress, and on this basis, it was not unreasonable to hypothesize that the cows on the once-daily milking regimen were stressed. Both psychological stress and pain are known to increase the secretion of cortisol in cows. It is possible that the reduction in milking frequency to once daily milking acted as a psychological stressor to the cows, as cattle seem to have a preference for more frequent milking, which correlates with the number of times a calf suckles the dam (4 to 5 times/d). Reducing milking frequency also increases the amount of milk that the

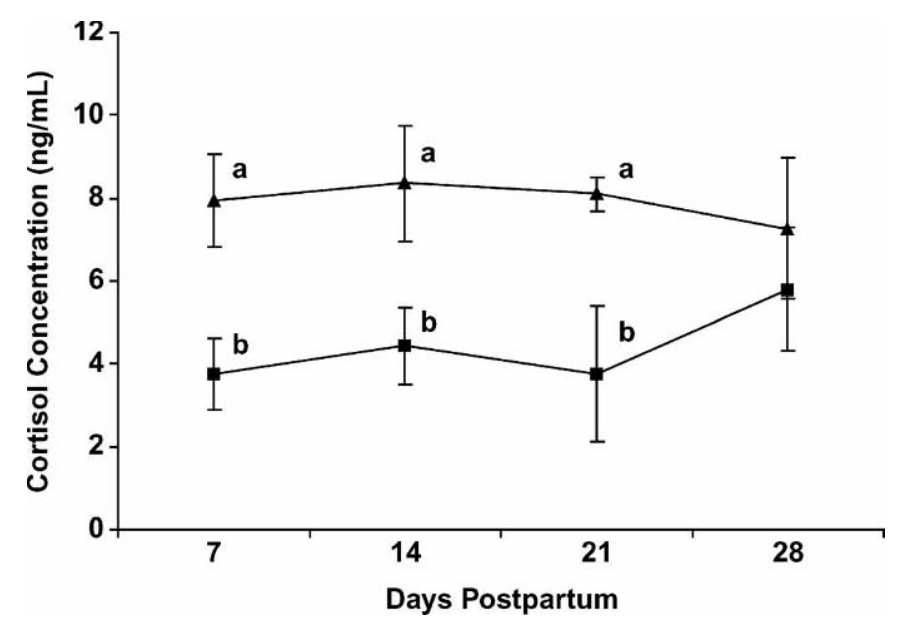

Figure 1. Mean ( \pm SEM; ng/mL) plasma cortisol concentrations of cows milked once ( $(\mathbf{\Delta})$ vs. 3 times ( $)$ daily for the first $28 \mathrm{~d}$ of lactation. ${ }^{\mathrm{a}, \mathrm{b}}$ Within time points, treatments with no common superscripts are different $(P<0.05)$. 
(a) NFKB p65

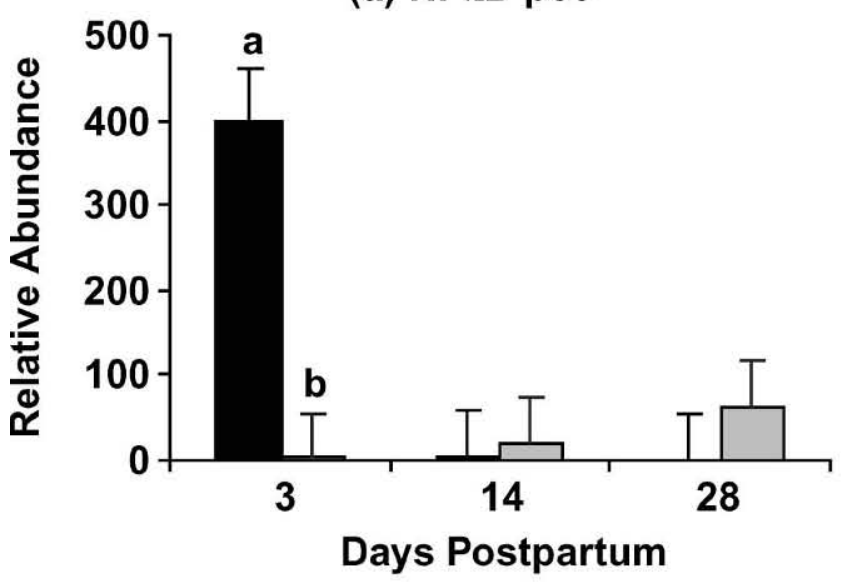

(c) XIAP

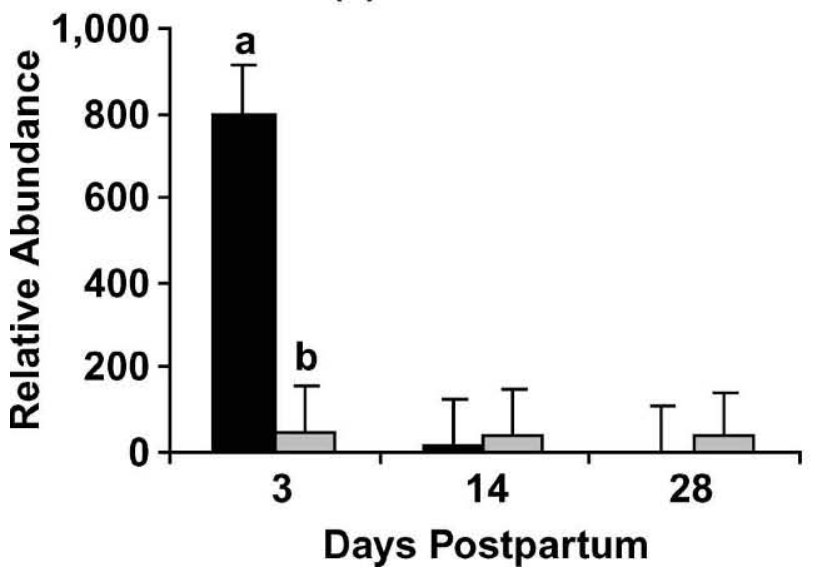

(b) I $\mathrm{I} \mathrm{B} \alpha$

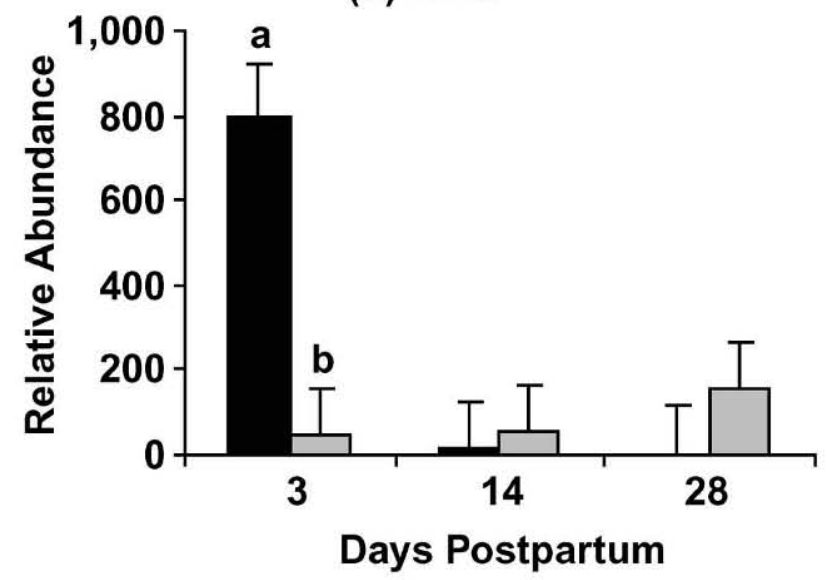

(d) HSP70

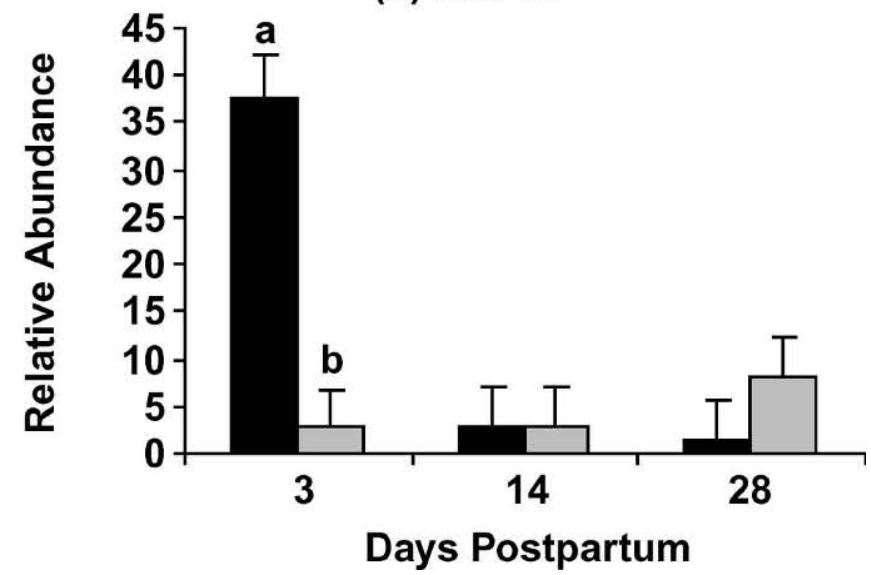

Figure 2. Least squares mean $( \pm \mathrm{SE})$ expression of nuclear factor $\kappa \mathrm{B}$ p65 subunit $(\mathrm{NF} \kappa \mathrm{B}$; a), $\mathrm{I} \kappa \mathrm{B} \alpha$; b), $\mathrm{X}$-linked inhibitor of apoptosis (XIAP; c), and d) heat shock protein 70 (HSP70; d) mRNA in neutrophils of cows milked once (solid bar) vs. 3 times (shaded bar) daily for the first $28 \mathrm{~d}$ of lactation. ${ }^{\mathrm{a}, \mathrm{b}}$ Within time points, treatments with no common superscripts are different $(P<0.001)$.

mammary gland must hold. It is not unreasonable to assume that distension of the udder in once-daily milked cows culminates in additional stress responses involving pain.

Cows milked once daily expressed higher relative quantities $(P<0.001)$ of the apoptosis regulatory genes nuclear factor $\kappa \mathrm{B}(\mathbf{N F} \kappa \mathbf{B})$ p65 subunit, $\mathrm{I} \kappa \mathrm{B} \alpha$, X-linked inhibitor of apoptosis (XIAP), and heat shock protein (HSP) 70, but only on d 3 postpartum (Figure 2). The $\mathrm{NF} \kappa \mathrm{B}$ is a key factor implicated in the modulation of apoptosis through its transcriptional regulation of over 150 metabolism, proinflammatory, and apoptosis genes. One family of $\mathrm{NF} \kappa \mathrm{B}$-dependent genes is the inhibitor of apoptosis (IAP), which encodes a family of apoptosis inhibitory proteins that includes XIAP; XIAP has been shown to bind to and potently inhibit caspases
3,7 , and 9 , thus blocking the apoptosis-inducing activities of these caspases. Heat shock proteins also regulate apoptosis, and their expression can be induced by many stressors (Garrido et al., 2001). Buzzard et al. (1998) and $\mathrm{Li}$ et al. (2000) demonstrated that elevated levels of HSP70 reduces or blocks caspase activation in addition to inhibiting apoptosis upstream of caspase 3 activation. Thus, our observations of elevated $\mathrm{NF} \kappa \mathrm{B}$ p65 subunit, XIAP, and HSP70 gene expression in neutrophils of the once-daily milked cows suggested that this management regimen induced the cells into an antiapoptotic state. However, increased expression of $\mathrm{I} \kappa \mathrm{B} \alpha$, a key inhibitor of $\mathrm{NF} \kappa \mathrm{B}$ activity, is contrary to a strictly anti-apoptotic reprogramming of the cells. Also, despite its documented role in bovine neutrophil survival induction and neutrophilia during parturition stress (Chang 
et al., 2004; Weber et al., 2004) and other stressful situations (Yagi et al., 2004), blood cortisol concentrations were not correlated $(P>0.05)$ with the gene expression changes or blood neutrophil counts we observed in the current study. The small number of animals in the study may explain this observation. A number of other important apoptosis regulatory genes were not monitored in this study, such as those that encode Bcl-2 family proteins and TNF-receptor family molecules. The expression and activity of these molecules are related to changes in circulating glucocorticoids during parturition (Chang et al., 2004; Burton et al., 2005) and transportation stress (Yagi et al., 2004). Because these families of molecules are directly responsible for the induction of spontaneous and death receptor-induced apoptosis in bovine neutrophils, future milking regimen experiments could be directed to examine their expression, activity, and consequences to neutrophil function and the health and productivity of periparturient dairy cows.

\section{REFERENCES}

Burton, J. L., S. A. Madsen, L.-C. Chang, P. S. D. Weber, K. R. Buckham, R. van Dorp, M.-C. Hickey, and B. Earley. 2005. Gene expression signatures in neutrophils exposed to glucocorticoids: A new paradigm to explain "neutrophil dysfunction" in parturient dairy cows. Vet. Immunol. Immunopathol. 105:197-219.
Buzzard, K. A., A. J. Giaccia, M. Killender, and R. L. Anderson. 1998. Heat shock protein 72 modulates pathways of stress-induced apoptosis. J. Biol. Chem. 273:17147-17153.

Chang, L.-C., S. A. Madsen, T. Toelboell, P. S. D. Weber, and J. L. Burton. 2004. Effects of glucocorticoids on Fas gene expression in bovine blood neutrophils. J. Endocrinol. 183:569-583.

Garrido, C., S. Gurbuxani, L. Ravagnan, and G. Kroemer. 2001. Heat shock proteins: Endogenous modulators of apoptotic cell death. Biochem. Biophys. Res. Commun. 286:433-442.

Keane, C. J., A. J. Hanlon, J. F. Roche, J. L. Burton, J. F. Mee, and T. Sweeney. The effect of once daily milking on neutrophil maturity and functional capacity in post-partum dairy cows. Res. Vet. Sci. (accepted).

Lee, A., M. K. Whyte, and C. Haslett. 1993. Inhibition of apoptosis and prolongation of neutrophil functional longevity by inflammatory mediators. J. Leukoc. Biol. 54:283-288.

Li, C. Y., J. S. Lee, Y. G. Ko, J. Kim, and J. S. Seo. 2000. Hsp70 inhibits apoptosis downstream of cytochrome c release and upstream of caspase-3 activation. J. Biol. Chem. 275:25665-25671.

Livak, K. J., and T. D. Schmittgen. 2001. Analysis of relative gene expression data using real-time quantitative PCR and the $2^{-\Delta \Delta C T}$ method. Methods 25:402-408.

Madsen, S. A., L.-C. Chang, M.-C. Hickey, G. J. M. Rosa, P. M. Coussens, and J. L. Burton. 2004. Microarray analysis of gene expression in blood neutrophils of parturient cows. Physiol. Genomics 16:212-221.

SAS Institute. 1989. SAS/STAT User's Guide. Version 6, 4th ed. SAS Inst., Inc., Cary, NC.

Weber, P. S. D., T. Toelboell, L.-C. Chang, J. Durrett Tirrell, P. S. Saama, G. W. Smith, and J. L. Burton. 2004. Mechanisms of glucocorticoid-induced down regulation of neutrophil L-selectin: Evidence for effects at the gene expression level and primarily on blood neutrophils. J. Leukoc. Biol. 75:815-827.

Yagi, Y., H. Shiono, Y. Chikayama, A. Ohnuma, I. Nakamura, and K.-I. Yayou. 2004. Transportation stress increases somatic cell counts in milk, and enhances the migration capacity of peripheral blood neutrophils of dairy cows. J. Vet. Med. Sci. 66:381-387. 